\title{
Pharmacy Compounding Quality Control and Pharmaceutical Development Strategies for Seventeen alpha Hydroxyprogesterone Caproate in Prevention of Preterm Delivery
}

\section{Zhao $\mathrm{Y}^{*}$, Caritis $\mathrm{S}^{2,3}$ and Venkataramanan $\mathrm{R}^{1,2,4,5,6}$}

${ }^{1}$ Department of Pharmaceutical Sciences, School of Pharmacy, University of Pittsburgh

${ }^{2}$ Magee Womens Research Institute

${ }^{3}$ Department of Obstetrics, Gynecology, and Reproductive Sciences, Magee Womens Hospital

${ }^{4}$ Department of Pathology, School of Medicine, University of Pittsburgh

${ }^{5}$ Thomas Starzl Transplantation Institute

${ }^{6} \mathrm{McGovern}$ Institute for Regenerative Medicine, Pittsburgh, Pennsylvania, USA

*Corresponding author: Zhao Y, Department of Pharmaceutical Sciences, School of Pharmacy, University of Pittsburgh, 718 Salk Hall, 3501 Terrace Street, Pittsburgh, PA 15213, Tel: 412-624-7913, E-mail: yaz41@ pitt.edu

Citation: Zhao Y, Caritis S, Venkataramanan R (2014) Pharmacy Compounding Quality Control and Pharmaceutical Development Strategies for Seventeen alpha Hydroxyprogesterone Caproate in Prevention of Preterm Delivery. J Pharm Drug Devel 2(2): 201. doi: 10.157444/2348-9782.1.401

Received Date: April 02, 2014 Accepted Date: April 09, 2014 Published Date: August 20, 2014

\section{Abstract}

Seventeen alpha hydroxyprogesterone caproate (17-OHPC) is the only FDA-approved drug labeled for prevention of preterm delivery. This drug is also available as a compounded product from licensed compounding pharmacies. This article reviews the FDA approval history and pharmacy compounding quality control data of 17-OHPC, as well as briefly discusses possible future pharmaceutical development strategies for 17-OHPC.

Keywords: Seventeen alpha hydroxyprogesterone caproate; Quality; Pharmaceutical development

\section{Introduction}

According to the March of Dimes, one in eight births in the United States is a preterm birth. Preterm birth, defined as childbirth occurring at $<37$ weeks of gestational age, is the leading cause of neonatal morbidity and mortality. Based on the promising effects seen in clinical trials [1,2] in reducing the risk of preterm birth, intramuscular injection of 17 alpha hydroxyprogesterone caproate (17-OHPC) has recently become the only Food and Drug Administration (FDA)-approved therapy labeled for reducing the risk of preterm birth in women with a singleton pregnancy who have a history of singleton spontaneous preterm birth. In addition to the FDA-approved product (Makena ${ }^{\circledast}$ ), compounded 17-OHPC prepared by licensed compounding pharmacies is also available for women with risk of preterm delivery.

Over $80 \%$ of clinical obstetricians have reported prescribing 17-OHPC for the prevention of preterm birth [3]. Disappointingly, the surveyed physicians reported that there was about half of eligible patients seen in their practice but not prescribed 17-OHPC [3], and the financial and logistical barriers carried the most weight (approximately 75\%) in the decision not to prescribe FDAapproved 17-OHPC to an eligible patient [4]. Additionally, thirty-nine percent of respondents had professional liability concerns regarding prescribing compounded 17-OHPC.

Furthermore, the current use of 17-OHPC oil formulation is largely empirical. From the perspective of pharmaceutical development, more therapeutically advantageous 17-OHPC formulations need to be explored.

Hence, the purpose of the present document is to summarize the quality control of compounded 17-OHPC and to this end discuss certain strategies for pharmaceutical development of 17-OHPC.

\section{Prevention of preterm birth by 17 alpha hydroxyprogesterone caproate}

The causes and mechanisms of preterm birth are not completely understood. Some of the known causes of preterm birth include short cervix, multiple pregnancies, infections and chronic conditions, such as diabetes and high blood pressure; however, often no cause can be specifically identified [5]. Most preterm births happen spontaneously. Consequently, several pharmacologic strategies, including tocolytics (e.g., oxytocin antagonists, betamimetics, calcium channel blockers, magnesium sulphate) [6], or progestational agents (e.g., vaginal progesterone [7], intramuscular 17-OHPC) have been employed to prolong pregnancy. 
The initial evidence that weekly injections of 17-OHPC improved the outcomes of selected high-risk pregnancies was shown in a small trial by Johnson in 1975 [8]. The 2003 landmark randomized placebo-controlled trial sponsored by the National Institute of Child Health and Human Development (NICHD) demonstrated a 34\% reduction in recurrent preterm birth before 37 weeks for singleton pregnant women who received compounded 17-OHPC versus a control group receiving placebo [1]. Based on the results of the 2003 trial [1,9], intramuscular 17-OHPC became the only FDA approved drug, for the prevention of preterm birth in singleton pregnant women with a history of a prior spontaneous preterm birth. The exact mode of action of 17-OHPC therapy in preventing preterm labor and delivery is not known [10]. Inhibition of tumor necrosis factor (TNF)-alpha-induced apoptosis in term fetal membranes by 17-OHPC may explain in part the mechanism by which 17-OHPC prevents preterm birth in some high-risk women [11]. The benefit of 17-OHPC to prolong pregnancy was neither demonstrated in women with short cervix [1215], nor in women with multiple pregnancies [16-18]. 17-OHPC had no effect on the pathways known to be involved in uterine contractility or quiescence. 17-OHPC had no effect on the cervical remodeling. Key mechanism by which 17-OHPC prevents preterm birth requires further study [19].

\section{Chemistry of 17 alpha hydroxyprogesterone caproate}

The long lasting and potent progestational activity of 17-OHPC on endometrium is attributed to its chemistry [20]. 17-OHPC is a synthetic progestin, an ester derivative of 17 alpha hydroxyprogesterone formed with caproic acid (hexanoic acid) [21]. It is not identified from natural body fluids or tissues in any living organism [21].

17-OHPC in solid state is a white to practically white crystalline powder with a molecular weight of 428.6, logarithm of partition coefficient $(\log \mathrm{P})$ of 5.88 , $\log$ arithm of distribution coefficient $(\log \mathrm{D})$ of 5.91 , hydrogen bond donors of 0 , hydrogen bond acceptors of 4, and water-insolubility [obtained from Pubmed (http://pubchem.ncbi.nlm.nih.gov/summary/summary.cgi?cid=12419\&loc=ec_ rcs) and Chemicalize (http://www.chemicalize.org/structure/\#!mol=hydroxyprogesterone+caproate\&source=fp)]. Due to the logP value $>5$ being highly lipophilic, 17-OHPC does not fully follow drug-likeness defined in the Lipinski's rule of five [22]. 17-OHPC is classified as class II drug according to the Biopharmaceutics Classification System (BCS) [23-26]. High lipophilicity of 17-OHPC leads to poor aqueous solubility [27]. Given the poor aqueous solubility, dissolution becomes the rate limiting step for the absorption of 17-OHPC from solid state to enter into systemic circulation.

\section{FDA approval history of 17 alpha hydroxyprogesterone caproate}

The FDA originally approved 17-OHPC with new drug application (NDA) 010347 in 1956 and NDA 016911 in 1972, under the trade name Delalutin ${ }^{\oplus}$ (17 alpha hydroxyprogesterone caproate) injection, held by Bristol Myers Squibb Company (BMS) [28]. Both NDA 010347 and NDA 016911 referenced the same drug product and utilized the same labeling. Delalutin ${ }^{\circledR}$ contained 250 $\mathrm{mg} / \mathrm{mL}$ of $17-\mathrm{OHPC}$ in castor oil, with $46 \%$ benzyl benzoate as a solvent and $2 \%$ benzyl alcohol as a preservative. The approved indications for Delalutin ${ }^{\oplus}$ injection, other than the indication for treatment of female hormone disturbances and advanced adenocarcinoma of the uterine corpus in non-pregnant women, also included threatened miscarriage. In the past, several generic forms (NDA 017439 by Watson Labs, NDA 018004 by Akorn, NDA 089330 and NDA 089331 by Quad Pharms) of Delalutin ${ }^{\bullet}$ injection were approved by FDA (Table 1). In 2000, FDA announced the withdrawal of approval of NDA 010347 and NDA 016911 for Delalutin $^{\otimes}$ at the request of the patent holder, BMS, due to the availability of superior treatments for uterine cancer, and not due to safety or efficacy reasons.

Shortly after the publication of the NICHD-sponsored study [1] in 2003, the American College of Obstetricians and Gynecologists (ACOG) Committee on Obstetric Practice issued a Committee Opinion recommending that progesterone supplementation to prevent preterm birth be considered for a select group of women (i.e., those with a prior spontaneous birth at $<37$ weeks of gestation) [29]. On February 3, 2011, based on the result of this NICHD-sponsored study, the FDA conditionally approved Makena ${ }^{\oplus}, 17$ alpha hydroxyprogesterone caproate injection by KV Pharmaceutical, under the Orphan Drug Act to reduce the risk of preterm delivery before 37 weeks of pregnancy, in pregnant women with a history of at least one spontaneous preterm birth.

\section{FDA-approved product and compounded version}

The FDA-approved product, Makena ${ }^{\circledR}$ is a clear, yellow, sterile, non-pyrogenic solution for intramuscular injection in $5 \mathrm{~mL}$ multidose vial containing $250 \mathrm{mg} / \mathrm{mL}$ of 17 alpha hydroxyprogesterone caproate $(25 \% \mathrm{w} / \mathrm{v})$, in castor oil $(28.6 \% \mathrm{v} / \mathrm{v})$ and benzyl benzoate $(46 \% \mathrm{v} / \mathrm{v})$ with the preservative benzyl alcohol $(2 \% \mathrm{v} / \mathrm{v})\left(\right.$ shown in Makena ${ }^{\oplus}$ label). Makena ${ }^{\oplus}$ is identical to Delalutin ${ }^{\oplus}$, the formulation that was previously approved. The approved dosage of 17-OHPC in pregnant women is weekly $250 \mathrm{mg}$ intramuscular injection, initiated from 16 weeks of gestation and continued until week 36 or delivery. The initial price of Makena ${ }^{\varpi}$ was set at $\$ 1,500$ per injection, compared with $\$ 10$ to $\$ 20$ for identical compounded version that has been used for decades before Makena ${ }^{\circledR}$ was approved. The total list price for a 20 -weeks supply of Makena ${ }^{\oplus}$ was approximately $\$ 30,000$ per pregnancy. The ACOG stated, "This price remains prohibitively high for a safe and effective treatment that is currently available at a much lower price in the form of compounded 17-OHPC" [9]. 


\begin{tabular}{|c|c|c|c|c|c|c|}
\hline Drug Name & NDA & Dosage Form/Route & $\begin{array}{c}\text { Strength, } \\
\mathrm{mg} / \mathrm{mL}\end{array}$ & Company & Approval timeline & $\begin{array}{c}\text { Marketing } \\
\text { Status }\end{array}$ \\
\hline DELALUTIN & 010347 & $\begin{array}{l}\text { Injectable; } \\
\text { Injection }\end{array}$ & 125,250 & $\begin{array}{l}\text { Bristol Myers } \\
\text { Squibb }\end{array}$ & 1956 & Discontinued \\
\hline DELALUTIN & 016911 & $\begin{array}{l}\text { Injectable; } \\
\text { Injection }\end{array}$ & 125,250 & $\begin{array}{l}\text { Bristol Myers } \\
\text { Squibb }\end{array}$ & 1972 & Discontinued \\
\hline 17-ОНРC & 017439 & $\begin{array}{l}\text { Injectable; } \\
\text { Injection }\end{array}$ & 125,250 & Watson Labs & 1974 & Discontinued \\
\hline 17-ОНPC & 018004 & $\begin{array}{l}\text { Injectable; } \\
\text { Injection }\end{array}$ & 125 & Akorn & 1979 & Discontinued \\
\hline 17-ОНРC & 089330 & $\begin{array}{l}\text { Injectable; } \\
\text { Injection }\end{array}$ & 125 & Quad Pharms & 1987 & Discontinued \\
\hline 17-ОНРC & 089331 & $\begin{array}{l}\text { Injectable; } \\
\text { Injection }\end{array}$ & 250 & Quad Pharms & 1987 & Discontinued \\
\hline MAKENA & 021945 & $\begin{array}{c}\text { Solution; } \\
\text { Intramuscular }\end{array}$ & 250 & KV Pharm & Feb, 2011 & Prescription \\
\hline
\end{tabular}

NDA: new drug application; 17-OHPC: 17 alpha hydroxyprogesterone caproate

Table 1: FDA approval history of 17 alpha hydroxyprogesterone caproate.

Shortly after the approval of Makena ${ }^{\oplus}$, in response to the harsh criticism from Congress and professional groups on Makena ${ }^{\circledR}$ pricing [4], in order to support access to this important drug, FDA did not intend to take enforcement action against pharmacies that compound hydroxyprogesterone caproate based on a valid prescription for an individually identified patient unless the compounded products are unsafe, of substandard quality, or are not being compounded in accordance with appropriate standards for compounding sterile products [30], and maintained that compounded versions would not violate the availability of FDA-approved drug Makena ${ }^{\oplus}$. This solution avoids excessive drug-related acquisition costs and provides patients with easy access to this important drug. The difference between Makena ${ }^{\circledR}$ and the compounded version of 17-OHPC, is the quality assurance provided by an FDA-approved product compared with the potential variability in quality associated with compounding practices of pharmacists who are trained to "compound and dispense" medications [4]. The composition of the compounded 17-OHPC consists of 250 $\mathrm{mg} / \mathrm{mL} 17-\mathrm{OHPC}$ in oily carriers, such as castor oil, sesame oil, olive oil or similar carriers, to which yet other excipients may, if desired, be added, such as benzyl alcohol and benzyl benzoate. Such addition is desirable in the preparation of 17-OHPC injection in order to, one hand enhance dissolution, the other hand lower the viscosity to make the preparation easier to be injected through a needle of the desired bore.

\section{Quality control of the active pharmaceutical ingredients and compounded products of 17 alpha hydroxyprogesterone caproate}

Recently, concern about the quality of the active pharmaceutical ingredient (API) used for compounding purpose as well as the quality of compounded 17-OHPC products have been expressed [31,32]. Inconsistent results (Tables 2 and 3) among different laboratories [31,33] based on the identical specification methods have been generated on the quality testing of API and compounded products of 17-OHPC. On June 15, 2012, FDA has stated that "although the analysis of this limited sample of compounded hydroxyprogesterone caproate products and APIs did not identify any major safety problems, approved drug products, such as Makena, provide a greater assurance of safety and effectiveness than do compounded products. One factor that the agency considers in determining whether a drug may be compounded is whether the prescribing practitioner has determined that a compounded product is necessary for the particular patient and would provide a significant difference for the patient as compared to the FDAapproved commercially available drug product" [33]. In addition, the safety and effectiveness of compounded 17-OHPC was confirmed in the pregnancy outcomes study of women receiving for prophylactic prevention of preterm birth [34].

Further, our stability-indicating study [35] (Table 4) also demonstrated that 17-OHPC appeared to be fairly stable when exposed for a short term to high temperature, light, strong acid, different preservatives, and different dispensing containers under respective experimental conditions. In addition, our recent studies [36,37] (Table 3) have shown acceptable content, sterility and pyrogenicity of 17-OHPC compounded by pharmacies in the USA. Soon after the publication of our research on testing the quality of compounded 17-OHPC, the American Journal of Obstetricians and Gynecologists editors commented that “... the Obstetrical-Fetal Pharmacology Research Units (OPRU)-funded investigators were able to perform the most extensive study to date of compounded 17-OHPC products ... The study ... demonstrates that compounded 17-OHPC should provide an effective, safe, and inexpensive alternative for patients who require treatment with 17-OHPC" [38]. 
Very recently, the FDA published a draft guidance on Pharmacy Compounding of Human Drug Products Under Section 503A of the Federal Food, Drug, and Cosmetic Act (FD\&C Act) $[39,40]$. Compounding conditions of section 503A include: (1) drug product is compounded for an identified individual patient based on a valid prescription order approved by a prescribing practitioner; (2) compounding is performed by a licensed practitioner in limited quantities; (3) drug product is compounded in compliance with the United States Pharmacopoeia (USP) chapters; (4) drug product is compounded using bulk drug substances that are manufactured by an FDA-registered establishment; (5) drug product is compounded using bulk drug substances with valid certificates of analysis; (6) drug product is compounded using ingredients (other than bulk drug substances) that comply with the standards of an applicable USP or NF monograph, if one exists, and the USP chapters on pharmacy compounding; (7) compounded drug product does not include products that have been withdrawn or removed from the market because such drug products or components of such drug products have been found to be unsafe or not effective; (8) the licensed practitioner does not compound any drug products that are essentially copies of commercially available drug products regularly or in inordinate amounts; (9) compounded drug product is not a drug product identified by FDA as a drug product that presents demonstrable difficulties for compounding that reasonably demonstrate an adverse effect on the safety or effectiveness of that drug product; (10) drug product is compounded in a state that has entered into a memorandum of understanding (MOU) with FDA that addresses the distribution of inordinate amounts of compounded drug products interstate and provides for appropriate investigation by a state agency of complaints relating to compounded drug products distributed outside such state; or in states that have not entered into such an MOU with FDA, the licensed practitioner does not distribute more than 5\% compounded drug products of the total prescription orders out of the state in which they are compounded. Following appropriate compounding conditions regarding a compounded product by compounding pharmacies may prevent or alleviate the reoccurrence of quality problems experienced with the use of compounded products by the New England Compounding Center (NECC, Framingham, MA). Since the NECC disaster in 2012 [41], the importance of correct procedures during every phase of customized pharmacy has been a focus of governmental interest and action as well as public scrutiny [42].

\begin{tabular}{|c|c|c|c|c|c|c|}
\hline Testing site & Sample size & Sample source & Assay & Total impurity & $\begin{array}{c}\text { Unidentified } \\
\text { impurity }\end{array}$ & $\begin{array}{c}\text { Safety } \\
\text { concerns }\end{array}$ \\
\hline FDA & 16 & $\begin{array}{c}\text { pharmacies, physicians, API } \\
\text { distributors, imported APIs } \\
\text { in US }\end{array}$ & Pass & Fail & No \\
\hline KV & 10 & $\begin{array}{c}\text { manufacturers not registered } \\
\text { with FDA and 3 repackagers } \\
\text { in US }\end{array}$ & Fail & Pass & Fail \\
\hline
\end{tabular}

NDA: nAPI: active pharmaceutical ingredient

Note: standard for assay: 97 - 103\%; standard for total impurity: $\leq 2 \%$; standard for unidentified impurity: $\leq 0.1 \%$

Table 2: Quality testing of the active pharmaceutical ingredient of 17 alpha hydroxyprogesterone caproate.

\begin{tabular}{|c|c|c|c|c|c|c|c|c|}
\hline Testing site & Sample size & Sample source & Potency & Impurity & BB & BA & Sterility & Endotoxin \\
\hline FDA & 13 & 8 pharmacies & $\begin{array}{c}12 / 13 \\
\text { pass }\end{array}$ & $\begin{array}{c}11 / 13 \\
\text { pass }\end{array}$ & NA & NA & NA & NA \\
\hline FDA & 26 & Samples retained from $\mathrm{KV}$ & $\begin{array}{c}23 / 26 \\
\text { pass }\end{array}$ & $\begin{array}{c}19 / 26 \\
\text { pass }\end{array}$ & NA & NA & NA & NA \\
\hline KV & 30 & 30 pharmacies & $\begin{array}{c}25 / 30 \\
\text { pass }\end{array}$ & $\begin{array}{c}13 / 30 \\
\text { pass }\end{array}$ & NA & NA & NA & NA \\
\hline $\begin{array}{c}\text { Our } \\
\text { laboratory }\end{array}$ & 3 & 1 pharmacy in Pittsburgh & $\begin{array}{l}3 / 3 \\
\text { pass }\end{array}$ & NA & NA & NA & pass & pass \\
\hline $\begin{array}{c}\text { Our } \\
\text { laboratory }\end{array}$ & 18 & 15 pharmacies over US & $\begin{array}{c}18 / 18 \\
\text { pass }\end{array}$ & Pass & Pass & Pass & pass & pass \\
\hline
\end{tabular}

PD: post-compounding duration; BB: Benzyl benzoate; BA: Benzyl alcohol; USP: the United States Pharmacopeia;

NA: not available

Note: standard for potency: $90-110 \%$; standard for impurity: $<0.2 \%$; standard for BB: $46 \%$; standard for BA: $2 \%$; standard for sterility by USP71: $90-110 \%$; standard for endotoxin by USP85: $<0.5 \mathrm{EU} / \mathrm{mg}$

Table 3: Quality testing of compounded 17 alpha hydroxyprogesterone caproate products.

\section{Pharmaceutical development strategies of 17-OHPC Dispensing 17-OHPC in single-dose container}

Delivery of 17-OHPC in single-dose container may be justified, in order to minimize patient dosing errors and reduce the risk of contamination that is associated with repeated use of multidose vials. Our studies indicated that both stability and sterility of 17OHPC over 19 weeks post-preparation were observed independent of the container size or material in which it was stored [36]. The FDA-approved product is dispensed in 5-mL multidose vials with weekly injections; the contents in a vial normally are consumed successively for 5 weeks. Likewise, if 1 - $\mathrm{mL}$ single-dose container is used, the patient can receive 20 injections for gestation of 16 till to 36 weeks and be more confident that the drug will not deteriorate or precipitate in that time frame. 


\begin{tabular}{|c|c|c|c|c|}
\hline $\begin{array}{l}\text { Experimental } \\
\text { conditions }\end{array}$ & Testing conditions & $\begin{array}{l}\text { Change in } \\
\text { Strength }\end{array}$ & $\begin{array}{l}\text { Change in } \\
\text { Impurity }\end{array}$ & Sterile/Pyrogen-free \\
\hline \multicolumn{5}{|l|}{ 17-OHPC powder } \\
\hline Heat & $150^{\circ} \mathrm{C}, 1$ hour & $\leftrightarrow$ & NA & NA \\
\hline Light & overall illumination $\geq 200 \mathrm{Wh} / \mathrm{m}^{2}, 3$ days & $\leftrightarrow$ & NA & NA \\
\hline In presence of acid & $5 \mathrm{M}$ hydrochloric acid, 72 hours & $\leftrightarrow$ & $\mathrm{D}$ & NA \\
\hline In presence of base & $5 \mathrm{M}$ sodium hydroxide, 5 hours & $\downarrow$ & $\uparrow$ & NA \\
\hline \multicolumn{5}{|c|}{ Compounded 17-OHPC products } \\
\hline Light & overall illumination $\geq 100 \mathrm{Wh} / \mathrm{m}^{2}, 10$ weeks & $\leftrightarrow$ & NA & NA \\
\hline Preservative & benzyl alcohol vs none, 10 weeks & $\leftrightarrow$ & NA & $\leftrightarrow$ \\
\hline Container & $\begin{array}{l}\text { 10-mL multidose glass vial vs } 1 \text {-mL glass vial vs } \\
1 \text {-mL plastic syringe, } 10 \text { weeks }\end{array}$ & $\leftrightarrow$ & NA & $\leftrightarrow$ \\
\hline Sterilization & Dry-heat, 2.5 hours vs filtration sterilization & $\leftrightarrow$ & $\leftrightarrow$ & NA \\
\hline $\begin{array}{l}\text { Storage duration } \\
\text { post-compounding }\end{array}$ & Up to 56 weeks & $\leftrightarrow$ & NA & $\leftrightarrow$ \\
\hline
\end{tabular}

NA: not available; $\uparrow$ : increase; $\downarrow$ : decrease; $\leftrightarrow$ : no change

Table 4: Impact of various experimental conditions on the quality of compounded 17 alpha hydroxyprogesterone caproate based on the data from our laboratory.

Furthermore, either a plastic syringe or a glass vial can be used to dispense 17-OHPC [36]. In principle, the high lipophilicity of 17-OHPC could lead to the binding of certain percentage of the drug onto the surface of a plastic container. Our findings do not support this concern [36]. The use of single-dose plastic syringe will enhance patients' and healthcare providers' convenience due to operational simplicity.

\section{Sterilization of 17-OHPC}

Dry-heat sterilization during compounding of 17-OHPC may be utilized to obtain more confidence in the safety of compounded products. Our study showed that the content of 17-OHPC in compounded products was not affected either by dry-heat sterilization or by filtration sterilization [35]. A critical step for safe 17-OHPC products involves assurance of sterility. FDA-approved product, Makena ${ }^{\oplus}$ is manufactured using filtration sterilization process. Sterilization by filtration is considered to have a sterility assurance level (SAL) of $10^{-3}$; that is, if one million units are sterilized, there will be one thousand sterilization failures. In contrast, dry-heat sterilization relative to filtration is considered be more effective allowing for terminally sterilization, with a SAL of $10^{-6}$ : one sterilization failure per million units sterilized.

\section{Preservative-free in 17-OHPC products}

Omitting the preservative in 17-OHPC products for an identified individual patient may be performed by compounding pharmacies. One ingredient added to current 17-OHPC products in order to avoid the alteration and degradation by microorganisms and to prolong the shelf life during storage is the preservative of benzyl alcohol. Our study demonstrated that 17-OHPC was stable and retained sterility over 10 weeks post-preparation without any pyrogen independent of preservative use [36]. This modification may have many potential benefits. Recently, the FDA cautioned about serious adverse events and death from the administration of benzyl alcohol to pregnant women and infants [43]. Our results suggest that omission of benzyl alcohol in compounded 17-OHPC in single dose vials does not pose substantial additional risk of infection to the mother and the fetus. Another potential benefit of modification in preservatives may be the avoidance of local skin reactions from current 17-OHPC formulation.

\section{Development of alternative dosage forms}

Our pharmacokinetic studies have shown low plasma concentrations $(0.02-0.16 \mu \mathrm{M})$ [44-46], large apparent volume of distribution $(9124$ - $69600 \mathrm{~L})$ [44,46], apparent overall clearance $(0.84 \mathrm{~L} / \mathrm{min})$ [46], and long half-life (16 days) [44] of 17-OHPC in pregnant women. Body mass index (BMI) has been found to be a covariate contributing to the interindividual differences in trough plasma concentrations and area under the curve (AUC) of 17-OHPC, with women of higher BMI having lower trough concentrations and lower AUC values [46]. The low plasma concentration of 17-OHPC may be due to extensive distribution of highly lipophilic 17-OHPC in lipid or adipose (fat) tissues. In addition, rapid CYP3A-mediated metabolism to hydroxylated metabolites has been observed upon incubation of 17-OHPC in human hepatic [47-49] and placental microsomes [49,50]. Our study based on in vitro interaction data in human liver microsomes also suggested that increased progesterone levels [51] or co-administrated medications during pregnancy may also account for some of the large variation in plasma 17-OHPC concentrations that is seen in 
pregnant patients who receive a fixed dose of medication. There is also a void in the complete understanding of the pharmacodynamics of 17-OHPC. Very limited evidence has indicated that the effectiveness of 17-OHPC in reducing preterm birth rates was influenced by the achieved plasma concentration [52]. A strong negative association $(\mathrm{P}<0.05)$ between plasma 17-OHPC concentration and the risk of spontaneous preterm birth was observed in that study. Women with plasma 17-OHPC concentrations in the lowest quartile had a significantly higher risk of spontaneous preterm birth $(\mathrm{P}=0.03)$ and delivered at significantly earlier gestational ages $(\mathrm{P}=0.002)$ than did women in the $2^{\text {nd }}$ to $4^{\text {th }}$ quartiles [52].

So far, intramuscular injectable is only available 17-OHPC treatment. Other formulations or administration of 17-OHPC by routes other than intramuscular may be considered. Firstly, oral dosage forms increase patients' compliance. 17-OHPC appears to be highly permeable based on its physico-chemical characteristics $(\log \mathrm{P}=5.88)$. In light of its stability under gastric $\mathrm{pH}$ environment [35], an oral product is probable if a formulation can be prepared to improve its solubility. However, the extensive metabolism by intestinal CYP3A on 17-OHPC would suggest a low oral bioavailability. Secondly, transdermal delivery system without the firstpass effect in the gut and liver, may be promising to achieve higher plasma concentrations for 17-OHPC. In addition, transdermal delivery contains additional reservoir that can effectively retard the release rate of the drug and decrease the dose frequency. However, drug load capacity through transdermal delivery may be relatively limited $(<250 \mathrm{mg})$. Vaginal administration route of 17-OHPC may provide women with a more user-friendly drug treatment than other methods and results in better patient compliance. Simultaneously, efficacy may be achieved via locally without compromise, while limiting the adverse effects from systemic exposure to 17-OHPC and simultaneously reducing potential induction of 17-OHPC on the metabolism of CYP2C19 substrates [53]. Drugs absorbed in the upper part of the vagina can bypass the liver and, if metabolized, are subject to a reduced hepatic firstpass effect. However, the assessment of the safety and efficacy of potential alternative formulations of 17-OHPC needs to be performed. Therefore, pharmaceutical development for 17-OHPC may be achievable. More thorough studies on its pharmacokinetics and pharmacodynamics should be given due attention.

\section{Conclusions}

The review specifically addresses the quality control of compounded version of 17-OHPC. The 2013 FDA draft guidance on Pharmacy Compounding of Human Drug Products emphasizes compounding human drug products under section 503A of the Federal Food, Drug, and Cosmetic Act. Some strategies of pharmaceutical development for 17-OHPC are also addressed.

\section{References}

1. Meis PJ, Klebanoff M, Thom E, Dombrowski MP, Sibai B, et al. (2003) Prevention of Recurrent Preterm Delivery by 17 Alpha-Hydroxyprogesterone Caproate. N Engl J Medn 348: 2379-85.

2. Facchinetti F, Dante G, Venturini P, Paganelli S, Volpe A (2008) 17alpha-hydroxy-progesterone effects on cervical proinflammatory agents in women at risk for preterm delivery. Am J Perinatol 25: 503-6.

3. Rebarber A, Fox N, Klauser CK, Saltzman D, Roman AS (2013) A national survey examining obstetrician perspectives on use of 17-alpha hydroxyprogesterone caproate post-US FDA approval. Clin Drug Investig 33: 571-7.

4. Patel Y, Rumore MM (2012) Hydroxyprogesterone caproate injection (makena) one year later: to compound or not to compound that is the question. P T 37: 405-11

5. WHO (2013) Preterm birth: World Health Organization Media centre, Geneva, Switzerland.

6. Haas DM, Caldwell DM, Kirkpatrick P, McIntosh JJ, Welton NJ (2012) Tocolytic therapy for preterm delivery: systematic review and network meta-analysis. Bmj 345: e6226.

7. Society for Maternal-Fetal Medicine Publications Committee, with assistance of Vincenzo Berghella (2012) Progesterone and preterm birth prevention: translating clinical trials data into clinical practice. Am J Obstet Gynecol 206: 376-86.

8. Johnson JW, Austin KL, Jones GS, Davis GH, King TM (1975) Efficacy of 17alpha-hydroxyprogesterone caproate in the prevention of premature labor. N Engl J Med 293: 675-80.

9. ACOG (2011) Makena Price Reduction Is Inadequate. The American College of Obstetricians and Gynecologists, Washington, USA.

10. Meis PJ (2005) 17 hydroxyprogesterone for the prevention of preterm delivery. Obstet Gynecol 105: 1128-35.

11. Luo G, Abrahams VM, Tadesse S, Funai EF, Hodgson EJ (2010) Progesterone inhibits basal and TNF-alpha-induced apoptosis in fetal membranes: a novel mechanism to explain progesterone-mediated prevention of preterm birth. Reprod Sci 17: 532-9.

12. Pessel C, Moni S, Zork N, Brubaker S, Vink J, et al. (2013) The effect of intramuscular progesterone on the rate of cervical shortening. American journal of obstetrics and gynecology 209: e261-7.

13. Lim AC, Schuit E, Papatsonis D, van Eyck J, Porath MM (2012) Effect of 17-alpha hydroxyprogesterone caproate on cervical length in twin pregnancies. Ultrasound Obstet Gynecol 40: 426-30.

14. Mackeen AD, Rafael TJ, Zavodnick J, Berghella V (2013) Effectiveness of 17-alpha-hydroxyprogesterone caproate on preterm birth prevention in women with history-indicated cerclage. Am J Perinatol 30: 755-8.

15. Grobman WA, Thom EA, Spong CY, Iams JD, Saade GR, et al. (2012) 17 alpha-hydroxyprogesterone caproate to prevent prematurity in nulliparas with cervical length less than $30 \mathrm{~mm}$. American journal of obstetrics and gynecology 207: 390.e1-8. 
16. Senat MV, Porcher R, Winer N, Vayssière C, Deruelle P, et al. (2013) Prevention of preterm delivery by 17 alpha-hydroxyprogesterone caproate in asymptomatic twin pregnancies with a short cervix: a randomized controlled trial. Am J Obstet Gynecol 208: 194.e1-8.

17. Caritis SN, Simhan HN, Zhao Y, Rouse DJ, Peaceman AM, et al. (2012) Relationship between 17-hydroxyprogesterone caproate concentrations and gestational age at delivery in twin gestation. American journal of obstetrics and gynecology 207: 396.e1-8.

18. Lim AC, Schuit E, Bloemenkamp K, Bernardus RE, Duvekot JJ, et al. (2011) 17alpha-hydroxyprogesterone caproate for the prevention of adverse neonatal outcome in multiple pregnancies: a randomized controlled trial. Obstet Gynecol 118: 513-20.

19. Nold C, Maubert M, Anton L, Yellon S, Elovitz MA (2013) Prevention of preterm birth by progestational agents: what are the molecular mechanisms? American journal of obstetrics and gynecology 208: 223.e1-7.

20. Schindler AE (2005) Role of progestogens for the prevention of premature birth. J Steroid Biochem Mol Biol 97: 435-8.

21. Romero R, Stanczyk FZ (2013) Progesterone is not the same as 17alpha-hydroxyprogesterone caproate: implications for obstetrical practice. American journal of obstetrics and gynecology 208: 421-6.

22. Lipinski CA, Lombardo F, Dominy BW, Feeney PJ (2001) Experimental and computational approaches to estimate solubility and permeability in drug discovery and development settings. Adv Drug Deliv Rev 46: 3-26.

23. Lee J, Burdette JE, MacRenaris KW, Mustafi D, Woodruff TK, et al. (2007) Rational design, synthesis, and biological evaluation of progesterone-modified MRI contrast agents. Chem Biol 2007 14: 824-34.

24. Tsai JC, Sheu HM, Hung PL, Cheng CL (2001) Effect of barrier disruption by acetone treatment on the permeability of compounds with various lipophilicities: implications for the permeability of compromised skin. J Pharm Sci 90: 1242-54.

25. Faassen F, Kelder J, Lenders J, Onderwater R, Vromans H (2003) Physicochemical properties and transport of steroids across Caco-2 cells. Pharm Res $20: 177-86$.

26. Press B (2011) Optimization of the Caco-2 permeability assay to screen drug compounds for intestinal absorption and efflux. Methods Mol Biol 763: 139-54.

27. Ali J, Camilleri P, Brown MB, Hutt AJ, Kirton SB (2012) In silico prediction of aqueous solubility using simple QSPR models: the importance of phenol and phenol-like moieties. J Chem Inf Model 52: 2950-57.

28. Drugs @ Food and Drug Administration, United States.

29. American College of Obstetricians and Gynecologists (2003) ACOG Committee Opinion. Use of progesterone to reduce preterm birth. Obstet Gynecol 102: $1115-6$.

30. FDA (2011) FDA Statement on Makena. U.S. Food and Drug Administration.

31. Chollet JL, Jozwiakowski MJ (2012) Quality investigation of hydroxyprogesterone caproate active pharmaceutical ingredient and injection. Drug Dev Ind Pharm 38: 540-9.

32. FDA (2011) FDA Statement on Makena. U.S. Food and Drug Administration.

33. FDA (2012) Updated FDA Statement on Compounded Versions of hydroxyprogesterone caproate (the active ingredient in Makena). U.S. Food and Drug Administration.

34. Sibai BM, Istwan NB, Palmer B, Stanziano GJ (2012) Pregnancy outcomes of women receiving compounded 17 alpha-hydroxyprogesterone caproate for prophylactic prevention of preterm birth 2004 to 2011. Am J Perinatol 29: 635-42.

35. Zhao Y, Bettinger J, Caritis SN, Venkataramanan R (2013) Characterization of Chemical Stability for 17alpha Hydroxyprogesterone Caproate. Am J Obstet Gynecol 208: 470.e1-5.

36. Caritis SN, Zhao Y, Bettinger J, Venkataramanan R (2013) Qualitative and quantitative measures of various compounded formulations of 17-alpha hydroxyprogesterone caproate. American journal of obstetrics and gynecology 208: 470.e1-470.e5.

37. Chang J, Zhao Y, Zhao WC, Venkataramanan R, Caritis SN (2014) Quality assessment of compounded 17-hydroxyprogesterone caproate. Am J Obstet Gynecol 210: 47.e1-7.

38. Cohen AW, Parry S (2014) Compounded 17-hydroxyprogesterone caproate is an inexpensive and safe alternative to the FDA-approved product. American journal of obstetrics and gynecology 210: 12-13.

39. FDA (2014) Guidance Pharmacy Compounding of Human Drug Products Under Section 503A of the Federal Food, Drug, and Cosmetic Act. U.S. Food and Drug Administration.

40. FDA (2012) FD\&C Act Chapter V. Drugs and Devices, Edited by Administration USFaD: U.S. Food and Drug Administration 156-157.

41. Multistate outbreak of fungal infection associated with injection of methylprednisolone acetate solution from a single compounding pharmacy - United States (2012) MMWR Morbidity and mortality weekly report 61: 839-42.

42. Brensel R, Brensel S, Ng A (2013) Improving the review of standard operating procedures: a novel electronic system for compounding pharmacies. International journal of pharmaceutical compounding 17: 465-75.

43. FDA (2011) Heparin Sodium injection. U.S. Food and Drug Administration.

44. Caritis SN, Sharma S, Venkataramanan R, Hankins GD, Miodovnik M, et al. (2012) Pharmacology and placental transport of 17-hydroxyprogesterone caproate in singleton gestation. American journal of obstetrics and gynecology 207: 398.e1-8.

45. Zhang S, Mada SR, Sharma S, Torch M, Mattison D, et al. (2008) Simultaneous quantitation of 17alpha-hydroxyprogesterone caproate, 17alpha-hydroxyprogesterone and progesterone in human plasma using high-performance liquid chromatography-mass spectrometry (HPLC-MS/MS). J Pharm Biomed Anal 48: 1174-80.

46. Caritis SN, Sharma S, Venkataramanan R, Rouse DJ, Peaceman AM, et al. (2011) Pharmacokinetics of 17-hydroxyprogesterone caproate in multifetal gestation. American journal of obstetrics and gynecology 205: 40.e1-8.

47. Sharma S, Ou J, Strom S, Mattison D, Caritis S, et al. (2008) Venkataramanan R: Identification of enzymes involved in the metabolism of 17alpha-hydroxyprogesterone caproate: an effective agent for prevention of preterm birth. Drug Metab Dispos 36: 1896-902.

48. Sharma S, Ellis EC, Dorko K, Zhang S, Mattison DR, et al. (2010) Metabolism of 17alpha-hydroxyprogesterone caproate, an agent for preventing preterm birth, by fetal hepatocytes. Drug Metab Dispos 38: 723-7. 
49. Yan R, Nanovskaya TN, Zharikova OL, Mattison DR, Hankins GD, et al. (2008) Metabolism of 17alpha-hydroxyprogesterone caproate by hepatic and placental microsomes of human and baboons. Biochem Pharmacol 75: 1848-57.

50. Fokina VM, Zharikova OL, Hankins GD, Ahmed MS, Nanovskaya TN (2012) Metabolism of 17-alpha-hydroxyprogesterone caproate by human placental mitochondria. Reprod Sci 19: 290-7.

51. Cuppett CD, Zhao Y, Caritis S, Zhang S, Zhao W, et al. (2013) Effect of endogenous steroid hormones on 17-alpha-hydroxyprogesterone caproate metabolism. Am J Obstet Gynecol 208: 86.e1-6.

52. Caritis SN, Venkataramanan R, Thom E, Harper M, Klebanoff MA, et al. (2014) Relationship between 17-alpha hydroxyprogesterone caproate concentration and spontaneous preterm birth. Am J Obstet Gynecol 210: 128.e1-6.

53. Zhao Y, Alshabi AM, Caritis S, Venkataramanan R (2014) Impact of 17-alpha-hydroxyprogesterone caproate on cytochrome P450s in primary cultures of human hepatocytes. Am J Obstet Gynecol pii: S0002-9378(14)00276-2.

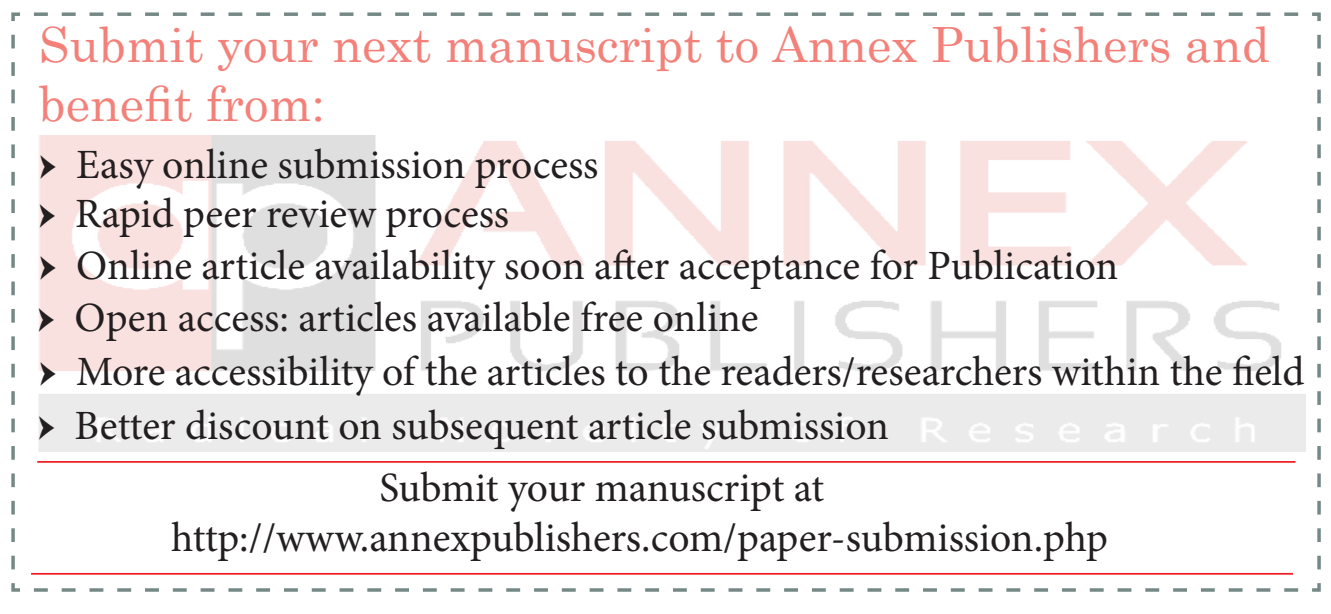

